\title{
Gene subtype analysis of Treponema pallidum for drug resistance to azithromycin
}

\author{
YUECUI LI, JIN LI, WEIYUE HU, HONGXIA LUO, JING ZHOU, CHENGHANG LI and CHUNJIAO CHEN \\ Department of Infectious Diseases, The First People's Hospital of Yongkang, Yongkang, Zhejiang 321300, P.R. China
}

Received August 13, 2017; Accepted January 8, 2018

DOI: $10.3892 /$ etm.2018.6241

\begin{abstract}
Azithromycin has been widely used for the treatment of Treponema pallidum. However, the drug resistance of $T$. pallidum for azithromycin is currently increasing. The aim of the present study was to analyze the association between gene subtypes of T.pallidum and drug resistance for azithromycin. The gene subtypes of T. pallidum were assayed by a polymerase chain reaction technique. Drug resistance of T. pallidum was analyzed using an antimicrobial susceptibility test. The results demonstrated that gene type tpr presented higher drug resistance compared with arp and tp0548 gene types of T. pallidum. Gene type tpr was identified as eight gene subtypes $(14 \mathrm{a} / \mathrm{f}, 14 \mathrm{e} / \mathrm{f}, 12 \mathrm{e} / \mathrm{f}, 12 \mathrm{~d} / \mathrm{f}, 6 \mathrm{~d} / \mathrm{f}, 11 \mathrm{~d} / \mathrm{f}, 14 \mathrm{j} / \mathrm{f}$ and $8 \mathrm{~d} / \mathrm{f}$ ) among 324 cases. It was identified that $23 \mathrm{~S}$ rRNA A2058G mutation was observed in gene subtypes 14a/f, 14e/f and $12 \mathrm{e} / \mathrm{f}$. A2059G mutation occurred in the gene subtypes $8 \mathrm{~d} / \mathrm{f}, 12 \mathrm{~d} / \mathrm{f}, 6 \mathrm{~d} / \mathrm{f}, 11 \mathrm{~d} / \mathrm{f}$ and $14 \mathrm{j} / \mathrm{f}$. The proportions of azithromycin-resistant genotypes harboring either the A2058G or the A2059G mutation among the T. pallidum strains were 34.2 and $65.8 \%$, respectively. The antimicrobial susceptibility test demonstrated that A2059G mutations exhibited a higher drug resistance for azithromycin compared with A2058G mutations. In conclusion, these results indicate that azithromycin resistance in T. pallidum is associated with gene subtype, which may contribute to the treatment of T.pallidum.
\end{abstract}

\section{Introduction}

Syphilis is a sexually transmitted disease caused by infection with the spirochete Treponema pallidum $(1,2)$. Previous studies have indicated that the occurrence of syphilis may result in severe complications, including dermatological diseases, neurosyphilis and cardiovascular syphilis, which remain key causes of morbidity worldwide $(3,4)$. In

Correspondence to: Dr Yuecui Li, Department of Infectious Diseases, The First People's Hospital of Yongkang, 599 Jinshan West Road, Yongkang, Zhejiang 321300, P.R. China

E-mail: liyuecuihospital@sina.com

Key words: Treponema pallidum, gene subtype, azithromycin, drug resistance addition, syphilis facilitates the infectivity and susceptibility to HIV infection in the clinic (5). Currently, the incidence of syphilis is increasing in multiple developed countries $(6,7)$. Although various treatments have been explored, including antibiotic therapy and antiviral therapy, these regimens are unsatisfactory, particularly in specific populations $(8,9)$. Therefore, early diagnosis and effective treatment of patients at the early stage of syphilis are essential for inhibition of T. pallidum infection.

Previous reports have indicated that antibiotic desensitization protocols may facilitate optimal and safe antibiotic therapy in the appropriate clinical setting for patients with T. pallidum infection (10). Alternative antibiotics treatments are widely used for patients with syphilis who are allergic to penicillin, including doxycycline, tetracycline, ceftriaxone, erythromycin and azithromycin $(11,12)$. Clinical trials have indicated that the efficacy of oral administration of azithromycin $(2.0 \mathrm{~g})$ is equivalent to that of benzathine penicillin $\mathrm{G}$ for the treatment of early syphilis in patients without HIV infection (13). However, drug resistance of $T$. pallidum for azithromycin attenuates its therapeutic efficacy for patients with syphilis (14). Molecular analysis has indicated that the acidic repeat protein (arp) gene, T. pallidum repeat (tpr) gene and tp0548 gene are associated with the drug resistance of T. pallidum $(15,16)$. Therefore, it is critical to analyze the association between gene subtypes of T. pallidum and drug resistance of azithromycin.

The objectives of this study were to analyze the association between gene subtype of T. pallidum and drug resistance to azithromycin. In this study, tpr-positive specimens were analyzed for the presence of A2058G and A2059G mutations and the relative drug resistance to azithromycin was determined among $T$. pallidum strains.

\section{Materials and methods}

Sample collection and molecular strain typing. A total of 132 blood samples were collected from female patients from the Yongkang region with primary syphilis in The First People's Hospital of Yongkang (Zhejiang, China) between May 2016 and June 2017. Patients with HIV or T. pallidum history were excluded from the present study. The protocols were approved by the Human Subjects Division of The First People's Hospital of Yongkang. All patients were required to provide written informed consent. T. pallidum strains were isolated from patient blood samples using sequencing-based typing or 
enhanced Centers for Disease Control and Prevention typing as described previously (17). DNA samples were tested for T. pallidum using quantitative polymerase chain reaction (PCR) targeting the polA gene (18).

DNA extraction. T. pallidum DNA was isolated as previously described (19). Briefly, DNA was extracted from $200 \mu 1$ of whole blood and DNAzol (Invitrogen; Thermo Fisher Scientific, Inc., Waltham, MA, USA) was used to extract DNA from specimens, according to the manufacturer's protocols. Strain typing was classified based on the analysis of three DNA target regions: (1) Restriction fragment length polymorphism analysis of sequence differences in the tpr gene; (2) the number of $60 \mathrm{bp}$ repeats in the $\operatorname{arp}$ gene; (3) sequence analysis of a short region of the tp0548 gene (20).

PCR methods. The PCR assay for T. pallidum analyzed the gene target polA as described previously (21). The primers used were as follows: F: 5'-CGTGTGGTATCAACTATGG-3', R: 5'-TCAACCGTGTACTCAGTGC-3'. All PCR products were analyzed using an ABI9700 GeneAmp PCR system (Applied Biosystems; Thermo Fisher Scientific, Inc.). PCR was performed in a $25 \mu \mathrm{l}$ reaction volume with $0.1 \mu \mathrm{g}$ DNA, $1.5 \mathrm{mM} \mathrm{MgCl}_{2}, 0.2 \mathrm{mM} \mathrm{dNTP}, 0.5 \mu \mathrm{M}$ primers and $0.5 \mu \mathrm{l}$ Taq polymerase (Takara Bio, Inc., Otsu, Japan). PCR conditions were as follows: $96^{\circ} \mathrm{C}$ for $5 \mathrm{~min}$, followed by 40 cycles at $95^{\circ} \mathrm{C}$ for $30 \mathrm{sec}, 56^{\circ} \mathrm{C}$ for $56 \mathrm{sec}$ and $72^{\circ} \mathrm{C}$ for $60 \mathrm{sec}$, followed by $72^{\circ} \mathrm{C}$ for $600 \mathrm{sec}$. PCR products were analyzed on a $1.5 \%$ agarose gel. Then, PCR products were visualized by staining with ethidium bromide and comparing with the molecular size markers of a 100- or 2,000-bp ladder (New England BioLabs, Inc., Ipswich, MA, USA).

Detection of drug resistance to azithromycin. The polA gene was amplified to detect resistance to azithromycin (22). Briefly, PCR amplification of the 23S rRNA gene of T. pallidum was treated by restriction enzyme digestion (MboII) as described previously $(23,24)$. PCR were performed in a $50 \mu 1$ reaction volume with $0.2 \mu \mathrm{g} \mathrm{rRNA}, 1.5 \mathrm{mM} \mathrm{MgCl}{ }_{2}, 0.2 \mathrm{mM} \mathrm{dNTP}$, $0.5 \mu \mathrm{M}$ primers (5'-GTGCCAGCMGCCGCGG-3') and $1.0 \mu \mathrm{l}$ Taq polymerase. PCR conditions were as follows: $95^{\circ} \mathrm{C}$ for $5 \mathrm{~min}$, followed by 35 cycles at $94^{\circ} \mathrm{C}$ for $30 \mathrm{sec}, 54^{\circ} \mathrm{C}$ for $57 \mathrm{sec}$ and $72^{\circ} \mathrm{C}$ for $60 \mathrm{sec}$, followed by $72^{\circ} \mathrm{C}$ for $600 \mathrm{sec}$. The azithromycin resistance genotypes were analyzed by DNA sequencing of the PCR products after purification with a QIAquick PCR purification kit (Qiagen, Inc., Valencia, CA, USA). T. pallidum DNA was also evaluated using restriction enzyme digestion for A2058G and A2059G mutations (MboII and BsaI, respectively; New England BioLabs, Inc.) (25). The DNA sequences were obtained using the DNA analyzer 3730xl (Applied Biosystems; Thermo Fisher Scientific, Inc.) and analyzed using DNASTAR ${ }^{\circledR}$ software version 3.0 (DNASTAR Inc., Madison, WI, USA).

Antimicrobial susceptibility testing. All antibiotic disks (azithromycin) were purchased from Abtek Biologicals Ltd. (Liverpool, UK). An antibiogram was performed on Mueller-Hinton agar for $12 \mathrm{~h}$ at $37^{\circ} \mathrm{C}$ to determine the antimicrobial agents resistance profiles to azithromycin $(10 \mu \mathrm{g})$ or PBS $(10 \mu \mathrm{g})$. Antimicrobial susceptibility was performed
Table I. Overview of tpr gene subtypes of Treponema pallidum.

\begin{tabular}{lcc}
\hline Gene type & A2058G & A2059G \\
\hline $14 \mathrm{a} / \mathrm{f}$ & + & - \\
$14 \mathrm{e} / \mathrm{f}$ & + & - \\
$12 \mathrm{e} / \mathrm{f}$ & + & - \\
$8 \mathrm{~d} / \mathrm{f}$ & - & + \\
$12 \mathrm{~d} / \mathrm{f}$ & - & + \\
$6 \mathrm{~d} / \mathrm{f}$ & - & + \\
$11 \mathrm{~d} / \mathrm{f}$ & - & + \\
$14 \mathrm{j} / \mathrm{f}$ & - & + \\
\hline
\end{tabular}

Genotype was determined using sequencing-based typing or enhanced Centers for Disease Control and Prevention typing.

according to the European Committee on Antimicrobial Susceptibility guidelines (26).

Statistical analysis. Data are expressed as mean \pm standard deviation of triplicate experiments. All data were analyzed using SPSS 17.0 software (SPSS, Inc., Chicago, IL, USA). Differences among groups were analyzed by one-way analysis of variance with Tukey's multiple comparisons test. $\mathrm{P}<0.05$ was considered to indicate a statistically significant difference.

\section{Results}

Comparison of the gene types of T. pallidum. DNA samples from 132 genital ulcer specimens were identified as T.pallidum positive, determined by PCR targeting the polA gene (Fig. 1A). Three gene types were observed among the $132 \mathrm{~T}$. pallidum positive specimens (Fig. 1B). The restriction digestion assay indicated that 78 samples were $t p r$ gene type, 24 were arp gene type and 30 were $t p 0548$ gene type. These results suggest that tpr is the most common gene type of T.pallidum.

Analysis of T. pallidum drug resistance to azithromycin. The antibiotic resistance of $T$. pallidum to azithromycin was analyzed in this study. As indicated in Fig. 2A, the restriction fragment length polymorphism analysis of the PCR amplicons from the representative samples (A2058G: 14a/f, 14e/f and 12e/f; A2059G: 8d/f, 12d/f, 6d/f, 11d/f, 14j/f.) revealed that 94 of the T. pallidum specimens were resistant to azithromycin. Gene type analysis indicated that the tpr gene type presented significantly higher drug resistance compared with the arp and tp0548 gene types (Fig. 2B). These results suggest that $t p r$ gene type may be associated with drug resistance of T. pallidum to azithromycin.

Comparison of the gene subtypes tpr of T. pallidum. The association between gene subtype tpr of T. pallidum and drug resistance was evaluated further. Eight subtypes of $t p r$ (14a/f, 14e/f, 12e/f, 12d/f, 6d/f, 11d/f, 14j/f, 8d/f) were identified among the 132 cases (Table I). It was identified that $23 \mathrm{~S}$ rRNA A2058G mutation was observed in gene subtypes 14a/f, 14e/f and 12e/f. A2059G mutation occurred in gene subtypes $8 \mathrm{~d} / \mathrm{f}, 12 \mathrm{~d} / \mathrm{f}, 6 \mathrm{~d} / \mathrm{f}, 11 \mathrm{~d} / \mathrm{f}$ and $14 \mathrm{j} / \mathrm{f}$. The proportion 

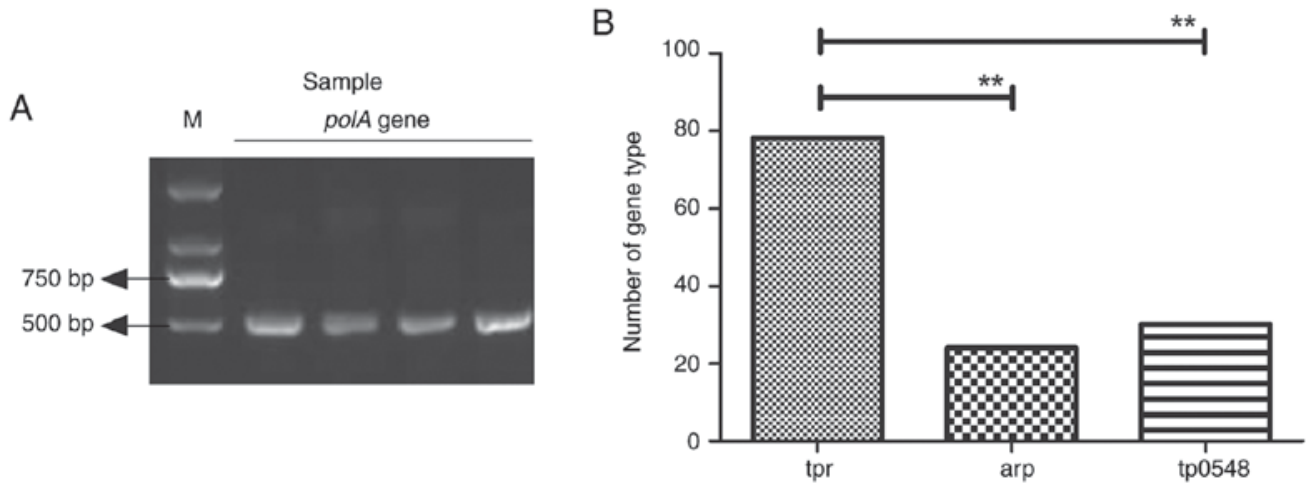

Figure 1. Comparison of the gene types of Treponema pallidum. (A) Identification of T. pallidum using PCR targeting the polA gene. (B) Gene type analysis in 132 T. pallidum specimens. ${ }^{* *} \mathrm{P}<0.01 . \mathrm{M}$, marker.

A

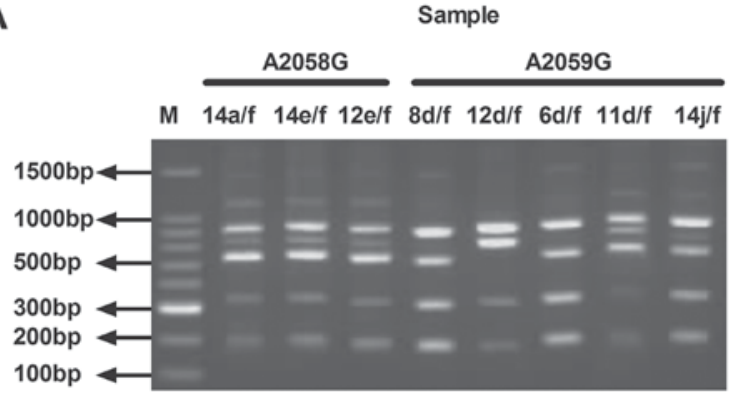

B

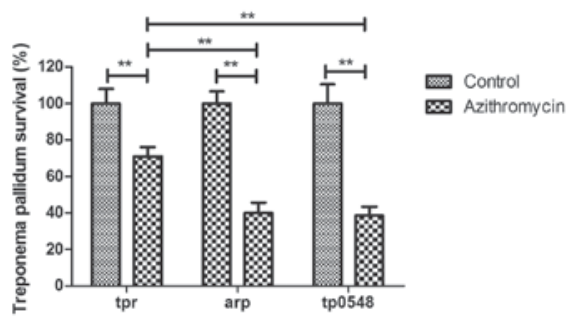

Figure 2. Analysis of Treponema pallidum drug resistance to azithromycin. (A) PCR products from representative samples used to analyze resistance to azithromycin in T. pallidum. (B) The tpr gene type presents higher drug resistance compared with the arp and tp0548 gene types of T. pallidum. M, marker. ${ }^{* *} \mathrm{P}<0.01$.

of azithromycin-resistant genotypes harboring either the A2058G or the A2059G mutation among T. pallidum was 65.8 and $34.2 \%$, respectively (Fig. 3). These results indicate that $t p r$ gene subtypes of $T$. pallidum may be associated with drug resistance to azithromycin.

Analysis of drug resistance of A2058G and A2059G mutations in gene subtype tpr of T. pallidum. The drug resistance of A2058G and A2059G mutations in gene subtype tpr of T. pallidum was investigated further. As indicated in Fig. 4A, A2059G mutation demonstrated a higher drug resistance for azithromycin compared with A2058G mutation, as determined by antimicrobial susceptibility test. The distribution of gene subtypes of T. pallidum with A2059G and A2058G mutation is presented in Fig. 4B and C. These results demonstrated that 14a/f of A2058G mutation and 12d/f of A2059G mutation frequently occurred in $t p r$ of $T$. pallidum. These results indicate that $\mathrm{A} 2058 \mathrm{G}$ and $\mathrm{A} 2059 \mathrm{G}$ mutations in gene subtype tpr of T. pallidum are associated with drug resistance to azithromycin.

\section{Discussion}

Molecular subtyping for T. pallidum has previously been explored in the $t p r$ gene and arp gene (27). A previous study also indicated that azithromycin treatment failures are associated with resistance in T. pallidum (28). However, the associations between molecular subtyping of T. pallidum and azithromycin resistance remain unclear. In the current study,

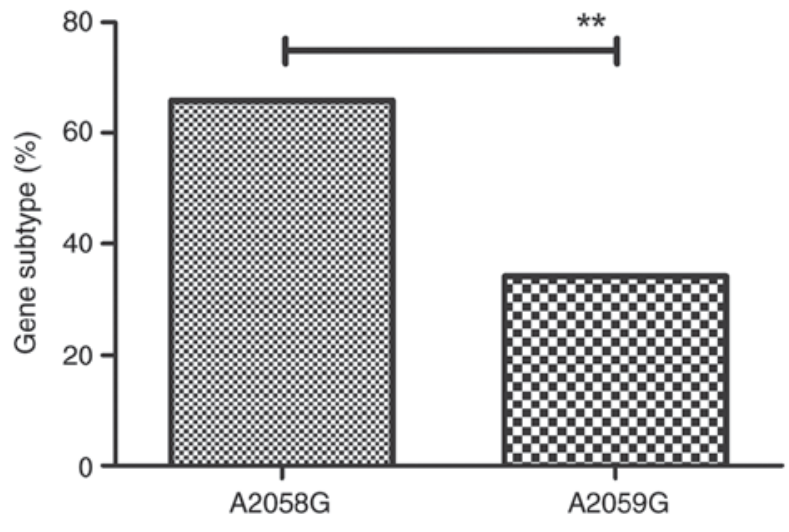

Figure 3. Proportion of azithromycin-resistant genotypes harboring either the A2058G or the A2059G mutation among Treponema pallidum samples. ${ }^{* * *} \mathrm{P}<0.01$.

the gene type of T. pallidum evaluated and azithromycin resistance was investigated in different gene types of T. pallidum. The results indicate that out of 132 samples, 78 were $t p r$ gene type, 24 were $\operatorname{arp}$ gene type and 30 were $t p 0548$ gene type specimens of T.pallidum. The findings suggested that $t p r$ gene type presented higher azithromycin resistance compared with arp and tp0548 gene type specimens of T. pallidum.

Currently, azithromycin is widely used for the treatment of T. pallidum in patients that are allergic to penicillin (29). Although the recommended azithromycin treatment for syphilis 
A

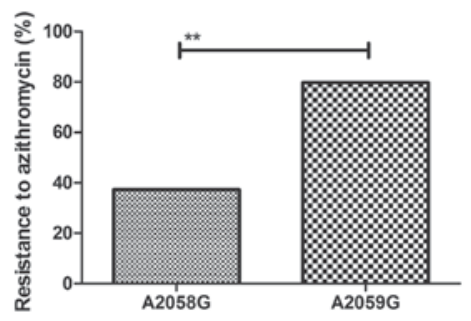

C

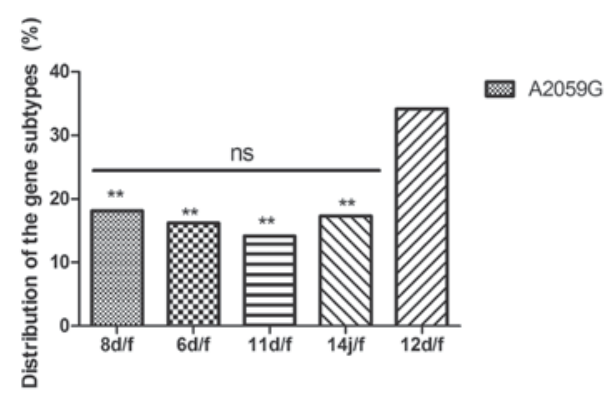

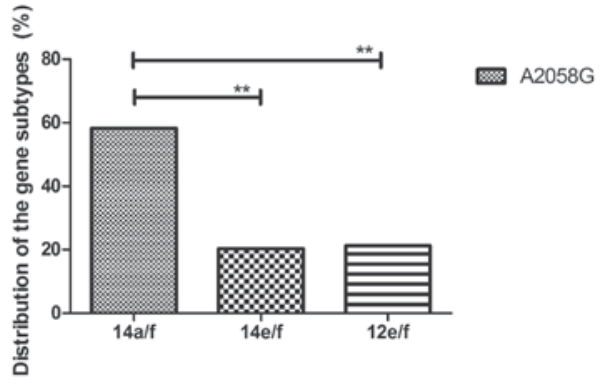

Figure 4. Analysis of drug resistance of A2058G and A2059G mutations in gene subtype tpr of Treponema pallidum. (A) A2059G mutation exhibits highe drug resistance for azithromycin compared with A2058G mutation. (B) Distribution of gene subtypes of T. pallidum with A2058G mutation. (C) Distribution of gene subtypes of T. pallidum with A2059G mutation. ${ }^{* *} \mathrm{P}<0.01 \mathrm{vs}$. the $12 \mathrm{~d} / \mathrm{f}$ group.

is effective, azithromycin resistance in T. pallidum has emerged and is increasing globally (30). It was observed that T.pallidum has developed azithromycin resistance to a varying extent (29). It has been identified that prevalence of azithromycin resistance is substantial in China and consequently that macrolides should not be used as a treatment option for early or incubating syphilis in China (31). The results of the current study identified three gene types, tpr, arp and tp0548, in 132 T. pallidum positive specimens from the Yongkang region. Reports have also indicated that restriction fragment length polymorphisms are associated with the drug resistance of T. pallidum $(32,33)$. In the current study, it was identified that 94 specimens of T. pallidum presented restriction fragment length polymorphisms, which were associated with drug resistance of T.pallidum for azithromycin. Notably, gene type analysis suggested that the tpr gene type presents higher drug resistance compared with the arp and tp0548 gene types of T. pallidum, which may be a potential target for addressing drug resistance to azithromycin.

A previous study indicated that tpr genes in T. pallidum are likely to be relevant to the pathogenesis of syphilis and drug resistance (34). A previous report described A2058G and A2059G mutations, which are associated with syphilis drug resistance to azithromycin (35). In the present study, the drug resistance to azithromycin of A2058G and A2059G mutations in tpr gene types of T.pallidum were compared. It was indicated that A2059G mutation demonstrated higher drug resistance for azithromycin compared with A2058G mutation. The findings also revealed that the gene subtypes of T. pallidum 14a/f of A2058G mutation and $12 \mathrm{~d} / \mathrm{f}$ of A2059G frequently occurred in tpr of T.pallidum, which may be a potential target for the treatment of syphilis. A limitation of the present study was that it did not explore the clinical treatment of azithromycin for patients with T. pallidum.
In conclusion, the current study identified that $12 \mathrm{~d} / \mathrm{f} t p r$ gene type of $T$. pallidum is the most common gene type for drug resistance to azithromycin. The findings suggest that A2059G mutation is associated with azithromycin resistance. Further investigation is required into the molecular mechanism of drug resistance of T. pallidum.

\section{Acknowledgements}

Not applicable.

\section{Funding}

No funding was received.

\section{Availability of data and materials}

The datasets used and/or analyzed during the current study are available from the corresponding author on reasonable request.

\section{Authors' contributions}

YL designed and performed the experiments. JL, WH, HL, JZ, $\mathrm{CL}$ and $\mathrm{CC}$ analyzed the experimental data and constructed the figures. The final version of the manuscript has been read and approved by all authors.

\section{Ethics approval and consent to participate}

The study protocol was approved by the Human Subjects Division of The First People's Hospital of Yongkang (Zhejiang, China). All patients provided written informed consent. 


\section{Consent for publication}

All patients provided written informed consent for the publication of their data.

\section{Competing interests}

The authors declare that they have no competing interests.

\section{References}

1. Stoltey JE and Cohen SE: Syphilis transmission: A review of the current evidence. Sex Health 12: 103-109, 2015.

2. Bristow CC, Larson E, Javanbakht M, Huang E, Causer L and Klausner JD: A review of recent advances in rapid point-of-care tests for syphilis. Sex Health 12: 119-125, 2015.

3. Hawkes SJ, Gomez GB and Broutet N: Early antenatal care: Does it make a difference to outcomes of pregnancy associated with syphilis? A systematic review and meta-analysis. PLoS One 8: e56713, 2013

4. Gomez GB, Kamb ML, Newman LM, Mark J, Broutet N and Hawkes SJ: Untreated maternal syphilis and adverse outcomes of pregnancy: A systematic review and meta-analysis. Bull World Health Organ 91: 217-226, 2013

5. Campos LN, Guimaraes MD, Carmo RA, Melo AP, Oliveira HN, Elkington K and McKinnon K: HIV, syphilis, and hepatitis B and $\mathrm{C}$ prevalence among patients with mental illness: A review of the literature. Cad Saude Publica 24 (Suppl 4): S607-S620, 2008

6. Naesens R, Vermeiren S, Van Schaeren J and Jeurissen A: False positive Lyme serology due to syphilis: Report of 6 cases and review of the literature. Acta Clin Belg 66: 58-59, 2011

7. Marinkovic Z and Dukic S: Historical and medical review of syphilis-afflicted army leaders, rulers and statesmen. Med Pregl 64: 423-427, 2011.

8. Seppings L and Hamill M: A review of an early syphilis outbreak in West Berkshire and Reading 2014-2015. Sex Transm Infect 92: $364,2016$.

9. Kenyon CR, Osbak $\mathrm{K}$ and Tsoumanis A: The Global Epidemiology of Syphilis in the Past Century-A systematic review based on antenatal syphilis prevalence. PLoS Negl Trop Dis 10: e0004711, 2016.

10. Magpantay G, Cardile AP, Madar CS, Hsue G and Belnap C: Antibiotic desensitization therapy in secondary syphilis and Listeria infection: Case reports and review of desensitization therapy. Hawaii Med J 70: 266-268, 2011.

11. Balaskas K, Spencer S and D'Souza Y: Peripapillary choroidal neovascularisation in the context of ocular syphilis is sensitive to combination antibiotic and corticosteroid treatment. Int Ophthalmol 33: 159-162, 2013

12. Kahn RH, Moseley KE, Johnson G and Farley TA: Potential for community-based screening, treatment, and antibiotic prophylaxis for syphilis prevention. Sex Transm Dis 27: 188-192, 2000.

13. Hook EW III, Behets F, Van Damme K, Ravelomanana N, Leone P, Sena AC, Martin D, Langley C, McNeil L and Wolff M: A phase III equivalence trial of azithromycin versus benzathine penicillin for treatment of early syphilis. J Infect Dis 201: $1729-1735,2010$

14. Read P, Jeoffreys N, Tagg K, Guy RJ, Gilbert GL and Donovan B: Azithromycin-resistant syphilis-causing strains in Sydney, Australia: Prevalence and risk factors. J Clin Microbiol 52: 2776-2781, 2014

15. Castro R, Prieto E, Aguas MJ, Manata MJ, Botas J and Pereira FM: Molecular subtyping of treponema pallidum subsp. pallidum in lisbon, portugal. J Clin Microbiol 47: 2510-2512, 2009.

16. Flasarova M, Smajs D, Matejkova P, Woznicova V, Heroldova-Dvorakova M and Votava M: Molecular detection and subtyping of Treponema pallidum subsp. Pallidum in clinical specimens. Epidemiol Mikrobiol Imunol 55: 105-111, 2006 (In Czech).

17. Mikalova L, Strouhal M,Cejkova D,Zobaníková M,PospíšilováP, Norris SJ, Sodergren E, Weinstock GM and Šmajs D: Genome analysis of Treponema pallidum subsp. Pallidum and subsp. pertenue strains: Most of the genetic differences are localized in six regions. PLoS One 5: e15713, 2010.
18. Chen CY, Chi KH, George RW, Cox DL, Srivastava A, Rui Silva M, Carneiro F, Lauwers GY and Ballard RC: Diagnosis of gastric syphilis by direct immunofluorescence staining and real-time PCR testing. J Clin Microbiol 44: 3452-3456, 2006.

19. Castro R, Aguas MJ, Batista T, Araujo C, Mansinho K and Pereira Fda L: Detection of Treponema pallidum Sp. Pallidum DNA in Cerebrospinal Fluid (CSF) by Two PCR Techniques. J Clin Lab Anal 30: 628-632, 2016.

20. Kondratiev NV, Alfimova MV and Golimbet VE: A search of target regions for association studies between DNA methylation and cognitive impairment in schizophrenia. Zh Nevrol Psikhiatr Im S S Korsakova 117: 72-75, 2017 (In Russian).

21. Pillay A, Liu H, Ebrahim S, Chen CY, Lai W, Fehler G, Ballard RC, Steiner B, Sturm AW and Morse SA: Molecular typing of Treponema pallidum in South Africa: Cross-sectional studies. J Clin Microbiol 40: 256-258, 2002.

22. Liu H, Rodes B, Chen CY and Steiner B: New tests for syphilis: Rational design of a PCR method for detection of Treponema pallidum in clinical specimens using unique regions of the DNA polymerase I gene. J Clin Microbiol 39: 1941-1946, 2001.

23. Jia S, Li J, Park SR, Ryu Y, Park IH, Park JH, Hong SS, Kwon SW and Lee J: Combined application of dispersive liquid-liquid microextraction based on the solidification of floating organic droplets and charged aerosol detection for the simple and sensitive quantification of macrolide antibiotics in human urine. J Pharm Biomed Anal 86: 204-213, 2013.

24. Haanpera M, Huovinen P and Jalava J: Detection and quantification of macrolide resistance mutations at positions 2058 and 2059 of the 23S rRNA gene by pyrosequencing. Antimicrob Agents Chemother 49: 457-460, 2005.

25. Lukehart SA, Godornes C, Molini BJ, Sonnett P, Hopkins S, Mulcahy F, Engelman J, Mitchell SJ, Rompalo AM, Marra CM and Klausner JD: Macrolide resistance in Treponema pallidum in the United States and Ireland. N Engl J Med 351: 154-158, 2004.

26. Kassim A, Omuse G, Premji Z and Revathi G: Comparison of clinical laboratory standards institute and european committee on antimicrobial susceptibility Testing guidelines for the interpretation of antibiotic susceptibility at a University teaching hospital in Nairobi, Kenya: A cross-sectional study. Ann Clin Microbiol Antimicrob 15: 21, 2016.

27. Tian H, Li Z, Li Z, Hou J, Zheng R, Li F, Liu R, Liu B, Wang C and Zhang F: Molecular typing of Treponema pallidum: Identification of a new sequence of tp0548 gene in Shandong, China. Sex Transm Dis 41: 551, 2014.

28. Prevalence of the 23 S rRNA A2058G point mutation and molecular subtypes in Treponema pallidum in the United States, 2007 to 2009. A2058G Prevalence Workgroup 39: 794-798, 2012.

29. Pandori MW, Gordones C, Castro L, Engelman J, Siedner M, Lukehart S and Klausner J: Detection of azithromycin resistance in Treponema pallidum by real-time PCR. Antimicrob Agents Chemother 51: 3425-3430, 2007.

30. Katz KA and Klausner JD: Azithromycin resistance in Treponema pallidum. Curr Opin Infect Dis 21: 83-91, 2008.

31. Chen XS, Yin YP, Wei WH, Wang HC, Peng RR, Zheng HP, Zhang JP, Zhu BY, Liu QZ and Huang SJ: High prevalence of azithromycin resistance to Treponema pallidum in geographically different areas in China. Clin Microbiol Infect 19: 975-979, 2013.

32. Chen CY, Chi KH, Pillay A, Nachamkin E, Su JR and Ballard RC: Detection of the A2058G and A2059G 23S rRNA gene point mutations associated with azithromycin resistance in Treponema pallidum by use of a TaqMan real-time multiplex PCR assay. J Clin Microbiol 51: 908-913, 2013.

33. Wu BR, Yang CJ, Tsai MS, Lee KY, Lee NY, Huang WC, Wu H, Lee $\mathrm{CH}$, Chen TC, Ko WC, et al: Multicentre surveillance of prevalence of the 23S rRNA A2058G and A2059G point mutations and molecular subtypes of Treponema pallidum in Taiwan, 2009-2013. Clin Microbiol Infect 20: 802-807, 2014

34. Giacani L, Molini B, Godornes C, Barrett L, Van Voorhis W, Centurion-Lara A and Lukehart SA: Quantitative analysis of tpr gene expression in Treponema pallidum isolates: Differences among isolates and correlation with T-cell responsiveness in experimental syphilis. Infect Immun 75: 104-112, 2007.

35. Matejkova P, Flasarova M, Zakoucka H, Borek M, Kremenová S, Arenberger P, Woznicová V, Weinstock GM and Smajs D: Macrolide treatment failure in a case of secondary syphilis: A novel A2059G mutation in the 23S rRNA gene of Treponema pallidum subsp. pallidum. J Med Microbiol 58: 832-836, 2009. 